\title{
Production and Characterization of Acyl Transfer Activity of Amidase from Alcaligenes sp. MTCC 10674 for Synthesis of Hydroxamic Acids
}

Bhatia Ravi Kant, Bhatia Shashi Kant, Mehta Praveen Kumar and Bhalla Tek Chand*

Department of Biotechnology Himachal Pradesh University, Summer Hill, Shimla (H.P) 171005, India

\begin{abstract}
Alcaligenes sp. MTCC 10674 has been isolated as a nitrile degrading bacterium from the soil. Amidase of this organism exhibited dual activity i.e. hydrolase as well as acyl transfer. The acyl transfer activity of this organism has been used for the synthesis of variety of hydroxamic acids. Optimization of physiochemical parameters resulted into 30 folds increase in the acyl transfer activity of amidase $\left(0.039 \mathrm{Umgdcm}^{-1}\right.$ to $\left.1.17 \mathrm{Umgdcm}^{-1}\right)$. The acyl transfer activity of amidase of this organism has broader substrate affinity ranging from a variety of aliphatic amides (formamide, acetamide, propanamide etc.) to aromatic amides (benzamide, mandelamide, nicotinamide etc.) along with hydroxylamine for the biotransformation of these amides into corresponding hydroxamic acid. This enzyme is quite stable at $50^{\circ} \mathrm{C}$ with $\mathrm{t}_{1 / 2}$ for $8 \mathrm{~h}$ and at $60^{\circ} \mathrm{C}$ this amidase have $t_{1 / 2}$ for $1.30 \mathrm{~h}$. The acyl transfer activity of amidase of Alcaligenes sp. MTCC 10674 under high temperature condition makes of potential application in developing a bioprocess for the production of variety of aliphatic and aromatic hydroxamic acid.
\end{abstract}

Keywords: Alcaligenes sp.; Amidase; Acyl transfer activity; Hydroxamic acid

\section{Introduction}

Amidase are an important group of enzymes belonging to nitrilase superfamily and are widely distributed in both prokaryotes and eukaryotes. These enzyme are involved in several metabolic pathways e.g. amide assimilation by breaking carbon and nitrogen bonds, amide degradation in prokaryotes and for the synthesis of many important growth factors in eukaryote system [1]. Amidase exhibited dual catalytic activities i.e., hydrolyzing in the aqueous environment and acyl transfer activity in the presence of hydroxylamine [2]. The hydrolase and acyl transfer activities of the amidase have been widely explored for the transformation of amides into commercially useful carboxylic acids and hydroxamic acid respectively $[1,3]$. Generally hydroxamic acids are synthesized chemically by Angeli-Rimini reaction or Loosen rearrangement [4]. However last several decades have witnessed drift from chemical routes to biochemical/biocatalyst routes for the synthesis of organic compounds. A number of amidases from microbial systems have been reported and explored for the acyl transfer activity [5]. Most of these are either thermolabile [3] or prone to substrate or product inhibitions [6]. Because of these operational problems these have limitations in the large scale synthesis of hydroxamic acids. In the present work various physiochemical parameters were optimized for maximum production of amidase and its acyl transfer activity was studied for synthesis of a variety of hydroxamic acids.

\section{Material and Methods}

\section{Chemicals}

All the chemicals were of analytical grade. The nitriles and amides were purchased from Lancaster Synthesis, England. Media components were from Hi Media (Mumbai) and the inorganic salts were from Merck (India).

\section{Microorganism}

Alcaligenes sp. MTCC 10674 earlier isolated in our laboratory as nitrile degrading bacterium and identified at the Institute of Microbial Technology (IMTECH), Chandigarh, India. It has been used as a source of amidase mediated acyl transfer activity.

\section{Preparation of Alcaligenes sp. MTCC 10674 for acyl transfer} activity

The cells of Alcaligenes sp. MTCC 10674 was grown aerobically in $250 \mathrm{ml}$ Erlenmeyer flasks containing $50 \mathrm{ml}$ of Nutrient broth medium and incubated at $30^{\circ} \mathrm{C}, 160 \mathrm{rpm}$ in an incubator shaker for 12 $\mathrm{h}$ to prepare preculture. Two percent $(\mathrm{v} / \mathrm{v})$ preculture $(\mathrm{OD}=2.4 \mathrm{AU})$ and isobutyronitrile $(0.2 \% \mathrm{v} / \mathrm{v})$ as inducer were added into $50 \mathrm{ml}$ of production medium [7] in a $250 \mathrm{ml}$ Erlenmeyer flasks. The cells of Alcaligenes sp. MTCC 10674 were incubated under the same conditions for $24 \mathrm{~h}$ and then harvested by centrifugation at $12,000 \mathrm{~g}$ for $5 \mathrm{~min}$ at $4^{\circ} \mathrm{C}$. The cells were washed thrice with $0.1 \mathrm{M}$ potassium phosphate buffer ( $\mathrm{pH}$ 7.0) and suspended in the same buffer (now called resting cells) and stored at $4^{\circ} \mathrm{C}$ until further use.

\section{Assay for acyl transfer activity}

Acyl transfer activity of amidase in resting cells of Alcaligenes sp. MTCC 10674 was assayed using the method developed by Brammar and Clarke [8]. The test reaction contained two substrates i.e., amide $(100 \mathrm{mM})$, hydroxylamine $(500 \mathrm{mM})$, potassium phosphate buffer $(0.1 \mathrm{M}) \mathrm{pH} 7.0$, and $4.0 \mathrm{mg}$ dry cell mass $(\mathrm{dcm})$ while in the enzyme control reaction. The reaction mixture was incubated at $50^{\circ} \mathrm{C}$ for $1 \mathrm{~h}$ and reaction was stopped by adding $1 \mathrm{ml}\left(6 \% \mathrm{FeCl}_{3}+2 \% \mathrm{HCl}\right)$ followed by centrifugation at $10,000 \mathrm{~g}$ for $5 \mathrm{~min}$ to remove the cells. The absorbance of the supernatant was recorded at $500 \mathrm{~nm}$. One unit of acyl transfer activity of amidase was defined as that amount of enzyme which converted one micromole of amide to hydroxamic acid per min under the assay conditions.

*Corresponding author: Bhalla Tek Chand, Department of Biotechnology, Himachal Pradesh University, Summer Hill, Shimla (H.P) 171005, India, Tel: 0177 2831948/2832154; E-mail: bhallatc@rediffmail.com

Received December 03, 2012; Accepted December 28, 2012; Published December 29, 2012

Citation: Ravi Kant B, Shashi Kant B, Praveen Kumar M, Tek Chand B (2013) Production and Characterization of Acyl Transfer Activity of Amidase from Alcaligenes sp. MTCC 10674 for Synthesis of Hydroxamic Acids. J Microb Biochem Technol 5: 001-005. doi:10.4172/1948-5948.1000090

Copyright: (c) 2013 Ravi Kant B, et al. This is an open-access article distributed under the terms of the Creative Commons Attribution License, which permits unrestricted use, distribution, and reproduction in any medium, provided the original author and source are credited 


\section{Physiological optimization for enzyme production}

The experiment one variable at a time (OVAT) was designed for maximum production of acyl transfer activity of amidase by optimizing culture conditions. A number of variables such as media (M1-M8), $\mathrm{pH}$ (5-10), temperature $\left(25^{\circ} \mathrm{C}-55^{\circ} \mathrm{C}\right)$, inducer (different types of amides and nitriles), inducer concentration (0.1\%-1.0\%), inoculum size (1$10 \%)$, rate of agitation (20-200 rpm) and incubation time $(0-72 \mathrm{~h})$ were taken into consideration for their effect on the production of acyl transfer activity.

\section{Thermal stability}

Thermal stability of acyl transfer activity of amidase from Alcaligenes sp. MTCC 10674 was evaluated by incubating the enzyme at different temperatures $\left(4^{\circ} \mathrm{C}, 30^{\circ} \mathrm{C}, 40^{\circ} \mathrm{C}, 50^{\circ} \mathrm{C}, 60^{\circ} \mathrm{C}\right)$ for $10 \mathrm{~h}$ and samples were withdrawn after an interval of $1 \mathrm{~h}$ for their acyl transfer activity.

\section{Substrate affinity}

Substrate affinity of the acyl transfer activity of amidase from this organism was tested by using $0.1 \mathrm{M}$ solution of each substrate i.e., formamide, acetamide, propanamide, butyramide, isobutyramide, thiocyanamide, benzamide, mandelamide, nicotinamide, sulphonilamide and $0.5 \mathrm{M}$ of hydroxylamine. Formation of the corresponding hydroxamic acid detected using acyl transfer activity assay.

\section{Results}

The production of enzymes by microorganisms is immensely influenced by physiological and environmental factors. Therefore, culture parameters like medium composition, temperature, $\mathrm{pH}$, inducer, inoculum size, etc. were optimized to enhance the production acyl transfer activity of Alcaligenes sp. MTCC 10674

\section{Medium}

Alcaligenes sp. MTCC 10674 was cultured in 8 different media (Table 1) and medium M6 proved to be the best for the production of acyl transfer activity. It seems that the salts favored higher production of acyl transfer activity in this medium M6 $\left(0.098 \pm 0.02 \mathrm{Umgdcm}^{-1}\right)$. Glucose $2 \mathrm{gl}^{-1}$ was added to this medium to increase the cell biomass $(0.12 \pm 0.01)$, which resulted into enhanced production of acyl transfer activity of amidase by Alcaligenes sp. MTCC 10674.

\section{Determination of medium $\mathrm{pH}$ effect}

The $\mathrm{pH}$ of the culture medium M6 was varied from 5.0-10.0. The effect of $\mathrm{pH}$ of medium on growth and acyl transfer activity production by Alcaligenes sp. MTCC 10674 is shown in figure 1. The growth of Alcaligenes sp. MTCC 10674 vary with the change in $\mathrm{pH}$ range of 5.010.0. Low $\mathrm{pH}$ (5.5-6.5) of medium had negative effect on growth and production of acyl transfer activity of the organism. At $\mathrm{pH} 7.5$ the growth of bacterial Alcaligenes sp. MTCC 10674 is slightly less than pH 7.0 but produced higher acyl transfer activity i.e., $(0.14 \pm 0.02$ $\mathrm{Umgdcm}^{-1}$ ).

\section{Temperature}

The Alcaligenes sp. MTCC 10674 was cultured at different temperatures ranging from $25-55^{\circ} \mathrm{C}$ (Figure 2) and acyl transfer activity was assayed. It has been found that there is an increase in the acyl transfer activity as well as in biomass production as the incubation temperature increased upto $30^{\circ} \mathrm{C}$. Alcaligenes sp. MTCC 10674 gave highest acyl transfer activity at $30^{\circ} \mathrm{C}\left(0.56 \pm 0.03 \mathrm{Umgdcm}^{-1}\right)$ with better

\begin{tabular}{llll}
\hline Media $(\mathrm{pH}-7.0)$ & Growth $\left(\mathrm{mgdcm} \mathrm{ml}^{-1}\right)$ & Activity $\left(\mathrm{U} \mathrm{mgdcm}^{-1}\right)$ & References \\
Control & $0.56 \pm 0.02$ & $0.039 \pm 0.02$ & {$[7]$} \\
M1 & $0.14 \pm 0.01$ & $0.035 \pm 0.02$ & Nutrient Broth \\
M2 & $0.16 \pm 0.02$ & $0.006 \pm 0.01$ & {$[9]$} \\
M3 & $0.18 \pm 0.02$ & $0.036 \pm 0.02$ & {$[10]$} \\
M4 & $0.20 \pm 0.03$ & $0.040 \pm 0.02$ & {$[11]$} \\
M5 & $0.14 \pm 0.01$ & $0.019 \pm 0.01$ & {$[12]$} \\
M6 & $0.12 \pm 0.02$ & $0.098 \pm 0.02$ & {$[13]$} \\
M7 & $0.15 \pm 0.04$ & $0.056 \pm 0.03$ & {$[14]$} \\
M8 & $0.17 \pm 0.01$ & $0.043 \pm 0.02$ & {$[15]$} \\
\hline
\end{tabular}

Table 1: Screening of some media for the production of acyl transfer activity by Alcaligenes sp. MTCC 10674.

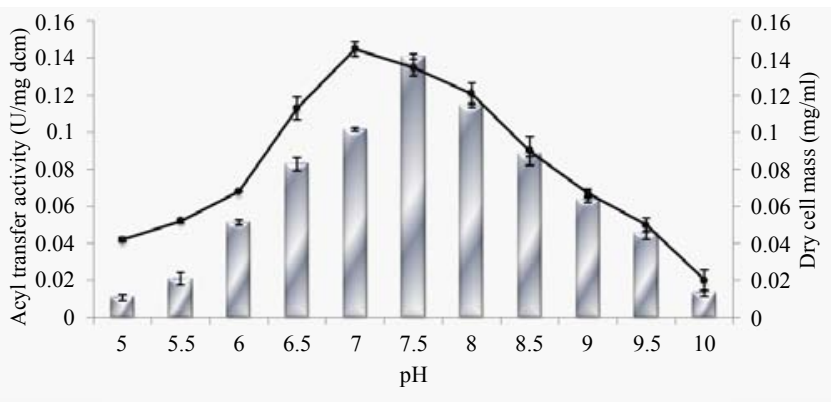

Figure 1: Effect of medium pH on ( $\overrightarrow{-}$ ) growth and production of ( $|\quad|$ ) acyl transfer activity by Alcaligenes sp. MTCC 10674 culture.

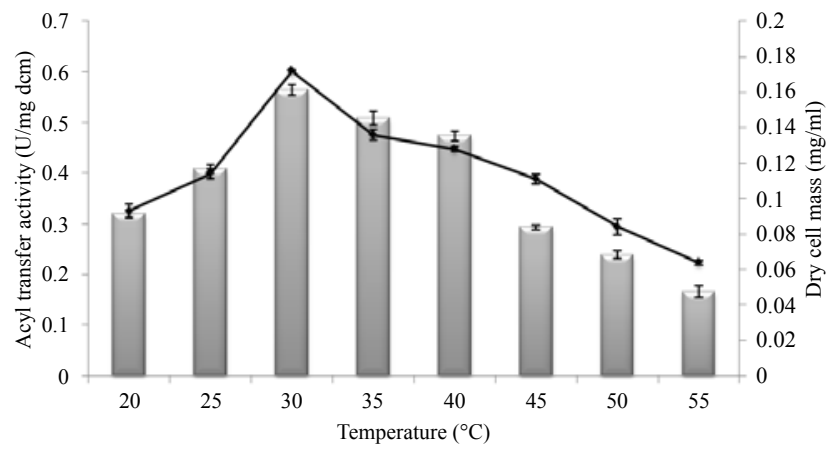

Figure 2: Effect of incubation temperature on ( $\rightarrow$ growth as well as on ( I ) acyl transfer activity production by Alcaligenes sp. MTCC 10674

biomass $(0.17 \pm 0.02 \mathrm{mg} / \mathrm{ml})$. As the isolate does not grew beyond $40^{\circ} \mathrm{C}$ and the production of acyl transfer activity also go on decline due to denaturation of required biological components. This organism was thus mesophilic in its requirements of temperature for the growth as well as for production of acyl transfer activity.

\section{Inoculums size}

The inoculum size $1-10 \%(\mathrm{v} / \mathrm{v})$ were used for the production of acyl transfer activity by Alcaligenes sp. MTCC 10674 and with 5\% (v/v) inoculum, the culture exhibited maximum acyl transfer activity $(0.68$ $\left.\pm 0.03 \mathrm{Umgdcm}^{-1}\right)$ as we as biomass $(0.22 \pm 0.02 \mathrm{mg} / \mathrm{ml}$ ) (Figure 3) which is seventeen times more than the initial acyl transfer activity. It has been found that biomass as well as acyl transfer activity increased upto $5 \%$ inoculum after that there was a slight decrease in the biomass 
production upto 10\% inoculum by Alcaligenes sp. MTCC 10674 but there is a rapid decrease in the acyl transfer activity.

\section{Determination of effect of different types of inducers}

The induction of acyl transfer activity of Alcaligenes sp. MTCC 10674 was done by adding different nitriles $(0.2 \% \mathrm{v} / \mathrm{v})$ and amides $(0.2 \%$ $\mathrm{w} / \mathrm{v})$ in the culture medium. Out of the 10 inducers tested in the present study some (isobutyronitrile, benzamide, propanamide) enhanced the biomass formation while some (acrylonitrile, N-Methyleacetamide, formamide) slowed down the growth of this organism vis-a-vis acyl transfer activity. The acyl transfer activity was induced in presence of the nitriles as well as amides, however, in the presence of nitriles there was some enhancement of growth too and isobutyronitrile emerged to be very effective inducer (Figure 4). An acyl transfer activity of 0.80 $\pm 0.02 \mathrm{Umgdcm}^{-1}$ was observed when isobutyronitrile was used as inducer with maximum production of biomass $(0.24 \pm 0.02 \mathrm{mg} / \mathrm{ml})$.

\section{Effect of inducer concentration}

The addition of isobutyronitrile in culture medium resulted in maximum induction of acyl transfer activity in Alcaligenes sp. MTCC 10674. Concentration of isobutyronitrile was varied from 0.1$1.0 \%(\mathrm{v} / \mathrm{v})$. After $24 \mathrm{~h}$ of incubation, hyper induction of acyl transfer activity $\left(0.92 \pm 0.02 \mathrm{Umgdcm}^{-1}\right)$ was observed with the addition of $0.4 \%$ isobutyronitrile in the medium (Figure 5 ). At lower and higher concentration than $0.4 \%$ of isobutyronitrile, a decline in the biomass and in acyl transfer activity production was noticed.

\section{Agitation rate}

The culture was grown at different agitation rates $(20-200 \mathrm{rpm})$ to enhance cell biomass and acyl transfer activity. It has been found that Alcaligenes sp. MTCC 10674 was an aerobic culture and produce maximum biomass $(0.34 \pm 0.03 \mathrm{mg} / \mathrm{ml})$ at $160 \mathrm{rpm}$ along with maximum acyl transfer activity $\left(1.04 \pm 0.02 \mathrm{Umgdcm}^{-1}\right)$. At slow agitation rate as the supply of oxygen was low, organism did not grow well and also exhibited a negative effect on acyl transfer activity production.

\section{Time of course of acyl transfer activity production}

In order to find out the appropriate time of incubation for the production of maximum acyl transfer activity by Alcaligenes sp. MTCC 10674, the organism was cultured under hitherto optimized culture conditions for $72 \mathrm{~h}$ and culture samples were withdrawn at an interval of $4 \mathrm{~h}$ till $72 \mathrm{~h}$ and acyl transfer activity was assayed. The results displayed in figure 6 depicted that the production of acyl transfer activity by Alcaligenes sp. MTCC 10674 is related with the biomass

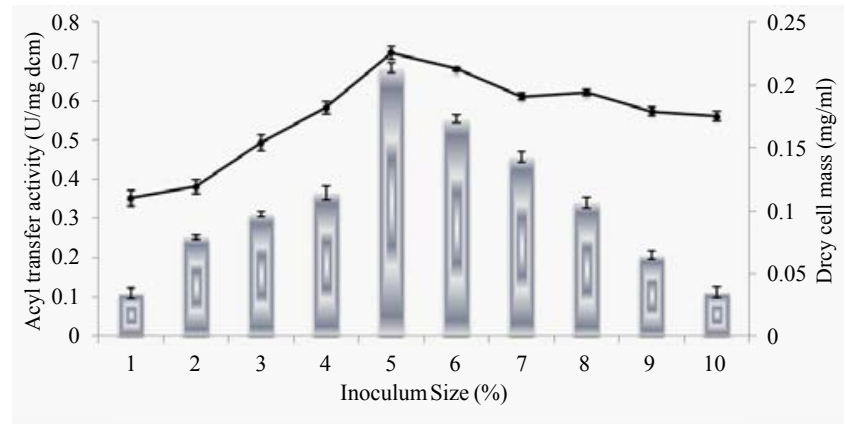

Figure 3: Effect of varying inoculum sizes on cell biomass (-) and on the production of acyl transfer activity ( I ) by Alcaligenes sp. MTCC 10674 .

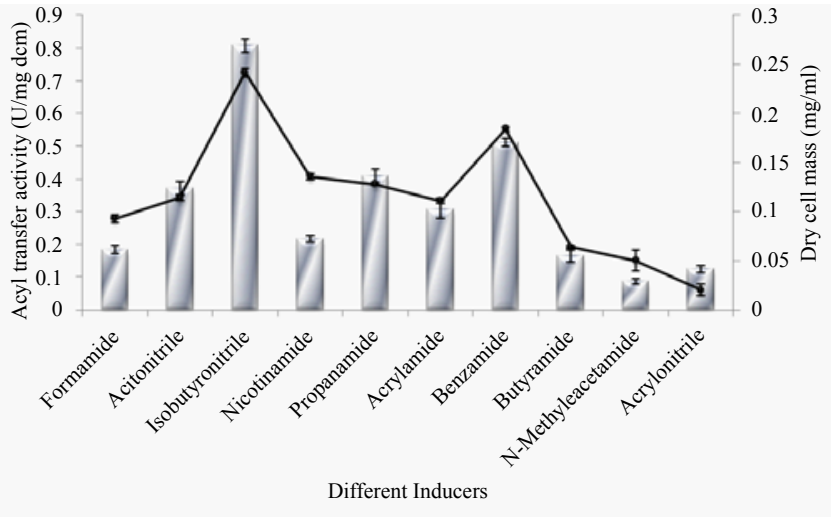

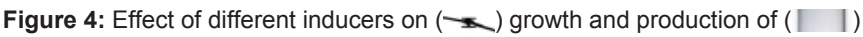
acyl transfer activity by Alcaligenes sp. MTCC 10674.

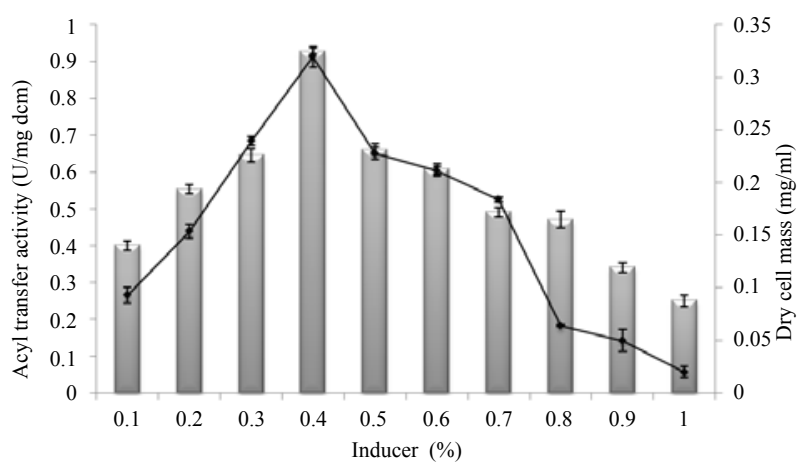

Figure 5: Effect of concentration of isobutyronitrile on the induction of acyl transfer activity ( $\mid$ ) and growth (-) in Alcaligenes sp. MTCC 10674.

production of the organism. The production of acyl transfer activity increased in the exponential phase of growth of Alcaligenes sp. MTCC 10674. The production of acyl transfer activity reached to its maximum value $\left(1.17 \pm 0.01 \mathrm{Umgdcm}^{-1}\right)$ at $32 \mathrm{~h}$ of incubation and after that there was a decline in the growth and enzyme production of Alcaligenes sp. MTCC 10674. The acyl transfer activity also showed some decline up to $44 \mathrm{~h}$ but after that there is a rapid fall in production of this enzyme.

\section{Thermal stability}

It has been found that the cells of Alcaligenes sp. MTCC 10674 exposed to $4^{\circ} \mathrm{C}$ and $30^{\circ} \mathrm{C}$ retained most of the acyl transfer activity but the cells stored at $40^{\circ} \mathrm{C}$ and $50^{\circ} \mathrm{C}$ exhibited fast decrease in acyl transfer activity as compared to the cells stored at $4^{\circ} \mathrm{C}$ and $30^{\circ} \mathrm{C}$. Above $30^{\circ} \mathrm{C}$ the enzyme was not stable, i.e., it started losing its acyl transfer activity as the incubation time progressed. The cells exposed at $60^{\circ} \mathrm{C}$ exhibited very rapid loss in acyl transfer activity (Figure 7).

\section{Substrate affinity of acyl transfer activity from Alcaligenes sp. MTCC 10674}

The acyl transfer activity of this organism was used for the biotransformation of a variety of amides with hydroxylamine to corresponding hydroxamic acids. The amidase from Alcaligenes sp. MTCC 10674 showed high acyl transfer activity for aromatic amides as 


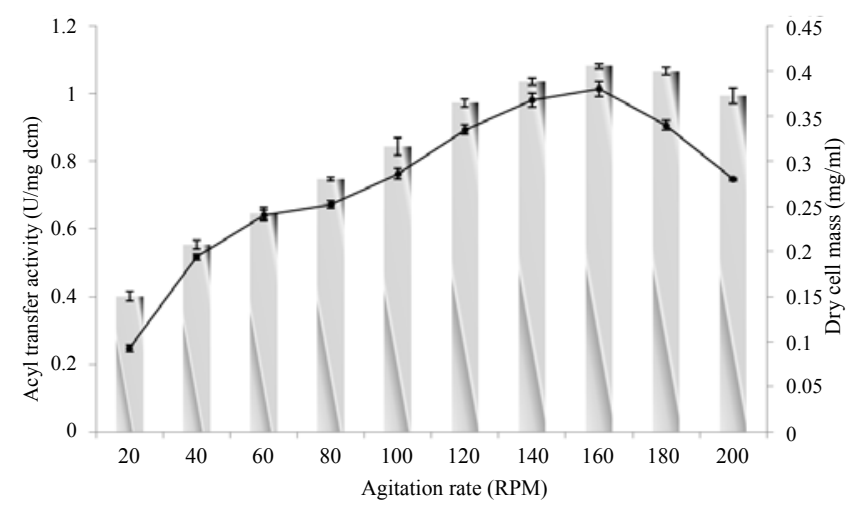

Figure 6: Effect of agitation rate on cell biomass (- and acyl transfer activity ( I ) production by Alcaligenes sp. MTCC 10674.

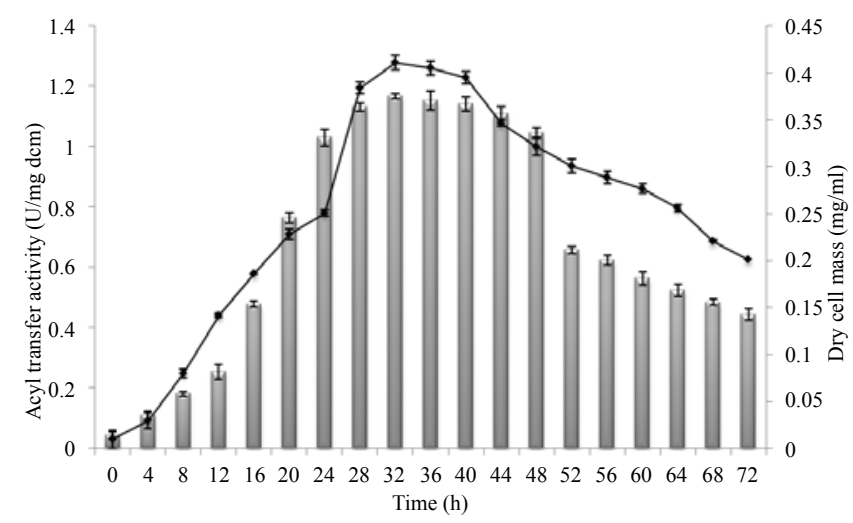

Figure 7: Time course for acyl transfer activity ( || $\mid)$ production vis-à-vis growth (-) of Alcaligenes sp. MTCC 10674

compared to the earlier published reports on similar enzymatic system. It has been observed that among aliphatic amides acetamide (1.71 $\mathrm{Umgdcm}^{-1}$ ) has maximum acyl transfer activity where as benzamide (among aromatic amides) reported highest acyl transfer activity $(0.98$ $\mathrm{Umgdcm}^{-1}$ ) from Alcaligenes sp. MTCC 10674 (Table 2).

\section{Discussion}

The enzyme mediated processes are gaining importance in the synthesis of fine chemicals and drug intermediates due to their operation under milder conditions. The present study was focused on the screening of Alcaligenes sp. MTCC 10674 isolate for assessing acyl transfer activity for various amides as substrates and to optimize its culture parameters to get maximum production of acyl transfer activity. R. rhodochrous J1 and Geobacillus pallidus was cultured in mineral salt medium for the production of acyl transfer activity respectively $[9,10]$. Similarly the Alcaligenes sp. MTCC 10674 showed highest acyl transfer activity in mineral salt medium when supplemented with glucose. However, this organism efficiently produced biomass and acyl transfer activity around neutral $\mathrm{pH}$ (7.5). Most of amidase producing organism which exhibit acyl transfer activity grow and produce enzyme around neutral $\mathrm{pH}[11,12]$. Alcaligenes sp. MTCC 10674 produced maximum acyl transfer activity at $30^{\circ} \mathrm{C}$ as reported for most of other amidase producing mesophilic organisms [13]. Generally acyl transfer activity of amidase is produced constitutively by many microbes [14-16] where as in some microorganisms it is induced by amides and nitriles [16, 17]. The acyl transfer activity of Alcaligenes sp. MTCC 10674 is inducible and isobutyronitrile $(0.4 \% \mathrm{v} / \mathrm{v})$ proved to be the best inducer. The growth of Alcaligenes sp. MTCC 10674 partially decreased at higher concentration of the inducer isobutyronitrile which might be due to toxicity of inducer and this also leads to decline in the acyl transfer activity production of this organism. Bhalla et al. and Linardi et al. $[13,18]$ respectively used

S. No. Substrate

Table 2: Affinity of different substrates for acyl transfer activity from Alcaligenes sp. MTCC 10674 


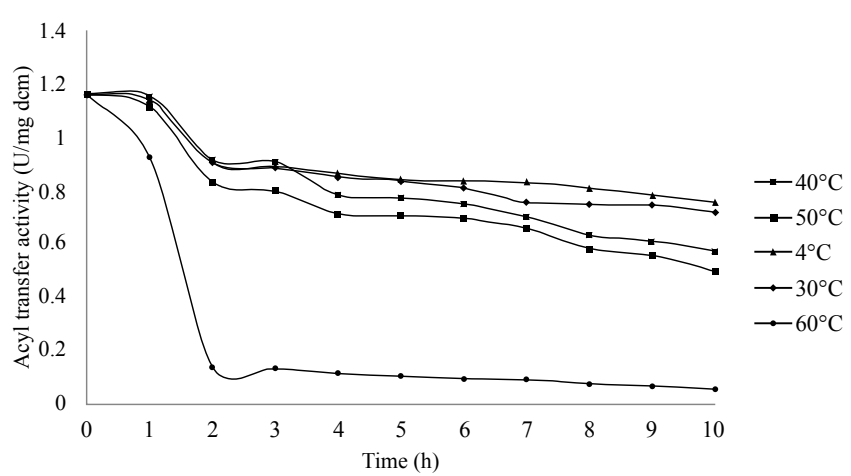

Figure 8: Effect of different storage temperatures on acyl transfer activity of Alcaligenes sp. MTCC 10674

$2.5 \%$ and $8 \%(\mathrm{v} / \mathrm{v})$ inoculum for the production of acyl transfer activity of amidase. This organism exhibited maximum acyl transfer activity when the production medium was seeded with $5 \%$ inoculums. Use of inoculum more than $5 \%$ resulted into decrease in the enzyme activity which might be due to faster depletion of nutrients in the medium. The induction of amidase for acyl transfer activity in Alcaligenes sp. MTCC 10674 was also observed in the log phase of growth which starts after $15 \mathrm{~h}$ of incubation and maximum acyl transfer activity was achieved after 32 h. However, R. rhodochrous J1 [9] and K. pneumoniae [19] have been reported to produce maximum amidase after $48 \mathrm{~h}$ of incubation. The amidase of G. pallidus RAPc8 was inactivated in $3 \mathrm{~h}$ at $50^{\circ} \mathrm{C}[3]$ while amidase of Geobacillus pallidus BTP-5x MTCC 9225 was stable up to $5 \mathrm{~h}$ at $50^{\circ} \mathrm{C}[2]$ due to denaturation of enzyme. Like most of the mesophilic amidases which rapidly lose their activity above $50^{\circ} \mathrm{C}$, the Alcaligenes sp. MTCC 10674 also lost its acyl transfer activity in $2 \mathrm{~h}$ on its exposer to $60^{\circ} \mathrm{C}$ but retained the acyl transfer activity for a long time when stored at $50^{\circ} \mathrm{C}$ for about $8 \mathrm{~h}$. The acyl transfer activity of this organism is capable in biotransformation formamide, acetamide, propanamide, butyramide, isobutyramide, thiocyanamide, benzamide, mandelamide, nicotinamide, sulphonilamide and hydroxylamine to corresponding hydroxamic acids. The acyl transfer activity of amidase from Alcaligenes sp. MTCC 10674 was higher for aromatic amides among the hitherto reported amidase systems $[3,5,6]$.

\section{Conclusion}

The present study reports a new isobutyronitrile induced amidase from Alcaligenes sp. MTCC 10674 that exhibited high acyl transfer activity for aromatic amides in comparison to earlier reported enzymatic systems (Figure 8). This amidase showed high acyl transfer activity towards the aromatic amides. Optimization of culture conditions led to 30 times increase in the production of acyl transfer activity by Alcaligenes sp. MTCC 10674. This can be used for the production of different industrially useful hydroxamic acids.

\section{Acknowledgement}

Authors are highly grateful to the University Grant Commission (UGC) New Delhi, India and Department of Biotechnology (DBT) Ministry of Science and Technology, India for providing the financial assistance in the form of JRF to Ravi Kant Bhatia and SRF to Shashi Kant Bhatia respectively. Computer facilities provided by Bioinformatics Center of Himachal Pradesh University duly acknowledged.

\section{References}

1. Sharma NN, Sharma M, Bhalla TC (2009) Amidases: versatile enzymes in nature. Rev Environ Sci Biotechnol 8: 343-366.
2. Sharma M, Sharma NN, Bhalla TC (2012) Biotransformation of Acetamide to Acetohydroxamic Acid at Bench Scale Using Acyl Transferase Activity of Amidase of Geobacillus pallidus BTP-5x MTCC 9225. Indian J Microbiol 52 76-82.

3. Makhongela HS, Glowacka AE, Agarkar VB, Sewell T, Weber B, et al. (2007) A novel thermostable nitrilase superfamily amidase from Geobacillus pallidus showing acyl transfer activity. Appl Environ Microbiol 75: 801-811.

4. Zheng WF, Chang ZY (2001) Synthesis of acetohydroxamic acid and determination of stability constants of its complexes with $\mathrm{Pu}(\mathrm{IV})$ and $\mathrm{Np}(\mathrm{IV})$. J of Nucl Radiochem 23: 1-6.

5. Fournand D, Bigey F, Arnaud A (1998) Acyl transfer activity of an amidase from Rhodococcus sp. Strain R312: formation of a wide range of hydroxamic acids. Appl Environ Microbiol 64: 2844-2852.

6. Vejvoda V, Martinkova L, Vesela AB, Kaplan O, Wahl SL et al. (2011) Biotransformation of nitriles to hydroxamic acids via a nitrile hydrataseamidase cascade reaction. J Mol Catal B Enzym 71: 51-55

7. Bhalla TC, Miura A, Wakamoto A, Ohba Y, Furuhashi K (1992) Asymmetric hydrolysis of $\alpha$-aminonitriles to optically active amino acids by a nitrilase of Rhodococcus rhodochrous PA-34. Appl Microbiol Biotechnol 37: 184-190.

8. Brammar WJ, Clarke PH (1964) Induction and repression of Pseudomonas aeruginosa amidase. J Gen Microbiol 37: 307-319.

9. Kobayashi M, Komeda H, Nagasawa T, Nishiyama M, Horinouchi S, et al. (1993) Amidase coupled with low-molecular-mass nitrile hydratase from Rhodococcus rhodochrous J1. Sequencing and expression of the gene and purification and characterization of the gene product. Eur J Biochem 217: 327-336.

10. Pereira RA, Graham D, Rainey FA, Cowan DA (1998) A novel thermostable nitrile hydratase. Extremophiles 2: 347-357.

11. Black TD, Briggs BS, Evans R, Muth WL, Vangala S, et al. (1996) O-Phthaly amidase in the synthesis of loracarbef, process development using this nove biocatalsyst. Biotechnology Letters 18: 875-880.

12. Pal A, Samanta TB (1999) $\beta$-Lactamase-Free Penicillin Amidase from Alcaligenes sp.: Isolation Strategy, Strain Characteristics, and Enzyme Immobilization. Curr Microbiol 39: 244-248.

13. Bhalla TC, Kumar J, Kumar H, Agrawal HO (1997) Amidase production by Rhodococcus sp. NHB-2. National Acadamy of Science Letters 20: 139-142.

14. Krieg L, Ansorge-Schumacher MB, Kula MR (2002) Screening for amidases: isolation and characterization of a novel D-amidase from Variovorax paradoxus. Adv Synth Catal 344: 965-973.

15. Robas N, Zouheiry H, Branlant G, Branlant C (1993) Improved penicillin amidase production using a genetically engineered mutant of Escherichia coli ATCC 11105. Biotechnol Bioeng 41: 14-24.

16. Baek DH, Song JJ, Lee SG, Kwon SJ, Asano Y, et al. (2003) New thermostable D-methionine amidase from Brevibacillus borstelensis BCS-1 and its application for D-phenylalanine production. Enzyme Microb Technol 32: 131-139.

17. Ciskanik LM, Wilczek JM, Fallon RD (1995) Purification and Characterization of an Enantioselective Amidase from Pseudomonas chlororaphis B23. Appl Environ Microbiol 61: 998-1003.

18. Linardi VR, Dias JC, Rosa CA (1996) Utilization of acetonitrile and othe aliphatic nitriles by a Candida famata strain. FEMS Microbiol Lett 144: 67-71.

19. Nawaz MS, Khan AA, Bhattacharayya D, Siitonen PH, Cerniglia CE (1996) Physical, biochemical, and immunological characterization of a thermostable amidase from Klebsiella pneumoniae NCTR 1. J Bacteriol 178: 2397-2401. 